\title{
A study of seasonal variations of gravity wave intensity in the lower thermosphere using LF D1 wind observations and a numerical model
}

\author{
N. M. Gavrilov ${ }^{1}$ and Ch. Jacobi ${ }^{2}$ \\ ${ }^{1}$ Saint-Petersburg State University, Department of Atmospheric Physics, Petrodvorets, 198904, Russia \\ ${ }^{2}$ University of Leipzig, Institute for Meteorology, 3 Stephanstrasse, 04103 Leipzig, Germany
}

Received: 22 June 2001 - Revised: 30 July 2002 - Accepted: 3 May 2003 - Published: 1 January 2004

\begin{abstract}
The data of the regular low-frequency D1 E-region observations at Collm, Germany $\left(52^{\circ} \mathrm{N}, 15^{\circ} \mathrm{E}\right)$ in $1983-$ 1999 are used for estimations of the intensity of short-period perturbations of the horizontal drift velocity at $85-110 \mathrm{~km}$ altitude. A simple half-hourly-difference numerical filter is used to extract perturbations with time scales of $0.7-3 \mathrm{~h}$.

The average monthly standard deviations of short-period perturbations of the zonal velocity near altitude $83 \mathrm{~km}$ have a main maximum in summer, a smaller maximum in winter, and minimum values at the equinoxes. At higher altitudes the summer maximum is shifted towards the spring months, and a second maximum of perturbation amplitudes appears in autumn at altitudes near and above $100 \mathrm{~km}$. The seasonal changes in the standard deviations of meridional velocity show the maxima in spring and summer. A numerical model describing the propagation of a set of harmonics modeling a spectrum of internal gravity waves in the atmosphere is used for the interpretation of observed seasonal variations of wind perturbation intensity. Numerical modeling reveals that the observed altitude changes in the seasonal variations of the drift velocity standard deviations may be explained by a superposition of IGWs generated at different levels in the troposphere and middle atmosphere. IGWs generated in the stratospheric and mesospheric jet stream may have substantial amplitudes at altitudes near and above $100 \mathrm{~km}$, where they may modify the seasonal variations, which are typical for IGWs propagating from the troposphere.
\end{abstract}

Key words. Meteorology and atmospheric dynamics (middle atmosphere dynamics; waves and tides) - Ionosphere (ionospheric irregularities)

\section{Introduction}

Internal gravity waves (IGWs) are supposed to be important for the formation of general circulation, thermal regime and

Correspondence to: N. M. Gavrilov

(gavrilov@ pobox.spbu.ru) composition of the middle and upper atmosphere. This determines an increased interest in the study of IGW climatology. Considerable information about IGWs in the middle atmosphere has been obtained with different ground-based and satellite techniques. One of the experimental methods, which can be used for IGW study at the altitudes $85-120 \mathrm{~km}$ is the D1 method observing drifts of ionospheric irregularities using low-frequency (LF) radio waves propagating from ground-based transmitters and reflecting from the lower ionosphere.

The LF D1 method has been used for measuring ionosphere drift velocities at altitudes between 80 and $120 \mathrm{~km}$ at the Collm Observatory of the University of Leipzig, Germany $\left(52^{\circ} \mathrm{N}, 15^{\circ} \mathrm{E}\right)$ since the International Geophysical Year, 1959 (Schminder and Kürschner, 1994). Fully automatic devices give the opportunities to obtain at least one drift velocity value per minute. The virtual reflection heights of radio waves are simultaneously measured since late 1982 (see Kürschner et al., 1987).

Systematic multi-year measurements at Collm gave substantial information about the mean winds, planetary waves and tides and about their seasonal and interannual variations (Schminder et al., 1994; Jacobi et al., 1997a, b). Besides these large-scale components, ionospheric drifts reveal strong fluctuations with periods from tens of minutes to hours. These perturbations may be connected with internal gravity waves (IGWs) propagating from the lower atmosphere. Gavrilov et al. (2001) developed and applied simple numerical filters to evaluate the seasonal and interannual variations of the intensity of the drift velocity perturbations having time scales from 0.7 to $3 \mathrm{~h}$.

To study the possible reasons for the variability in the seasonal behavior of IGW intensity observed at Shigaraki with the Japanese Middle and Upper atmosphere (MU) radar, Gavrilov and Fukao (1999) applied a numerical model describing the vertical propagation of a set of wave harmonics modeling the atmospheric IGW spectrum. The model includes realistic vertical profiles of background winds and temperature, IGW dissipation due to turbulent and molecular 
viscosity and heat conduction, ion drag and radiative heat exchange, and wave filtering at critical levels, due to the total reflection of the wave energy.

Many IGW sources exist in the atmosphere. There are the theories of IGW generation by mountains (Nastrom and Fritts, 1992; McLandress and McFarlane, 1993; Chunchuzov, 1994), by shear instability in jet streams (Fritts, 1984; Hamilton, 1984; Lindzen, 1984; Fritts and Nastrom, 1992), and by convection (Manzini and Hamilton, 1993; Pfister et al., 1993; Alexander, 1996). An important source of waves of different scales in the atmosphere is turbulence ranging from the microscale to the synoptic scale. The generation of sound by small-scale turbulence was studied by Lighthill (1952, 1978). Mesoscale IGWs are generated by mesoscale turbulent motions (Stein, 1967; Townsend, 1965; Drobyazko and Krasilnikov, 1985).

Gavrilov and Fukao (1999) made calculations for a set of IGW harmonics with a range of frequencies: horizontal wavelengths, phase speeds and azimuths of propagation, which represent an ensemble of waves propagating from nonlinear hydrodynamic sources randomly distributed in the atmosphere. These calculations reproduce the seasonal cycles of IGW amplitudes having a maximum in winter and a minimum in summer in the upper troposphere and having maxima in winter and summer and minima at equinoxes in the mesosphere. The seasonal behavior at different altitudes appears to be produced by the seasonal variations of the background wind and temperature, which influence the IGW generation and propagation.

In the present paper we applied the numerical model of Gavrilov and Fukao (1999) to interpret a possible change in the seasonal variations of short-period perturbations of ionospheric drift velocity at altitudes $85-110 \mathrm{~km}$ observed using the LF D1 method at Collm. A comparison of contributions from IGW hydrodynamic sources located both in the lower and middle atmosphere is made.

\section{Measurements of IGW intensity at Collm}

The similar-fade method is used at Collm Observatory (about $52^{\circ} \mathrm{N}, 15^{\circ} \mathrm{E}$ ) for determination of horizontal drifts of ionospheric plasma at altitudes $85-110 \mathrm{~km}$ with the lowfrequency (LF) D1 method. In this method the fading of a radio signal propagates from a ground-based transmitter and is then reflected from the ionosphere and recorded at three points located at the corners of a right-angled triangle, separated by distances of the order of one wavelength or less.

At Collm Observatory the amplitude modulated carrier waves from three commercial broadcasting stations working at frequencies of 177,225 and $272 \mathrm{kHz}$ and located at distances of 170, 460 and $400 \mathrm{~km}$, respectively, are used. The receivers are placed on the ground at the corners of a rightangled triangle with equal sides of $300 \mathrm{~m}$ along the zonal and meridional directions. At Collm, an algorithmised form of the similar-fade method is used, which is based on the estimation of the time differences between corresponding fading maxima and minima at the three receivers (Kürschner, 1975; Schminder and Kürschner, 1994). The individual pairs of the time differences, which correspond to the ionospheric drift velocity, are measured at a time resolution of $0.25 \mathrm{~s}$. The data are combined to half-hourly zonal and meridional mean drift velocity values for each frequency, the mean values being averaged over 30-60 individual velocity values. Only a few half-hourly means can be obtained during daylight time, due to absorption of the radio waves in the D-region of ionosphere, which is stronger in summer due to the longer time interval of daylight hours then. This results in a total of about 700 and 1200 half-hourly mean values per month in summer and winter, respectively.

Since late 1982, the virtual height, $h$, is measured on the frequency $177 \mathrm{kHz}$ using travel time differences between the ground and sky radio waves (Kürschner et al., 1987) on a modulation side band near $1.8 \mathrm{kHz}$. The standard deviation of the individual $h$ values is about $2 \mathrm{~km}$. The relation of the measured virtual height $h$ to the real height $z$ depends on the electron density profile, which is unknown during the measurements. However, we use relations between $h$ and $z$ (e.g. Jacobi et al., 1997b) that are based on full wave field calculations performed by Singer (1975), using the mean electron density profiles. The relations give $z$ values $1-2 \mathrm{~km}$ smaller than $h$ at an altitude of $100 \mathrm{~km}$, with the difference decreasing at lower altitudes. Standard deviations of half-hourly mean heights (essentially caused by the natural variability of individual reflection heights) are about $3 \mathrm{~km}$ below the altitude of $95 \mathrm{~km}$ and about $5 \mathrm{~km}$ near $100 \mathrm{~km}$. As is the case with the drift measurements, particularly in summer, during daylight hours only, few measurements can be performed due to the absorption of the sky wave.

Using the described procedures, Collm measurements give a series of half-hourly values of zonal, $u$, and meridional, $v$, components of drift velocity during any day. In the present study we use only data for the frequency $177 \mathrm{kHz}$ after the year 1983, for which we also have half-hourly mean values of the reflection heights $z$. To estimate the intensity of shortperiod perturbations of the drift velocity, we use a simple numerical filter for calculating the differences of the mentioned successive half-hourly drift velocities and take only pairs with differences in their heights of less than $d z=3 \mathrm{~km}$, to minimize possible apparent wind variations due to height changes in the case of a vertical gradient of the mean wind. Calculations show that a decrease in the limit $d z$ to 2,1 and $0 \mathrm{~km}$ gives practically the same values of the variances $\bar{u}^{\prime 2}$ and $\bar{v}^{2}$ as we have for $d z=3 \mathrm{~km}$, but using $d z=3 \mathrm{~km}$ allows us to increase the statistical reliability of the results.

Calculating the differences of half-hourly values with the previous half-hourly averaging of the data is equivalent to a numerical filter with the power transmission function described by Gavrilov et al. (2000). The filter passes harmonics with periods at $\tau \sim 0.7-3 \mathrm{~h}$ with a maximum at $\tau \sim 1 \mathrm{~h}$. The filter transmission function is not dependent on whether the selected pairs of data are consecutive or randomly distributed in time and space. Therefore the filter transmission function is especially suitable to be used for the interpreta- 
tion of LF D1 measurements with substantial height changes during a day.

For each pair of data involved into the analysis we calculated the hourly mean height and drift velocity. The results are arranged in height layers of $10 \mathrm{~km}$ in thickness, with varying nominal centers. For each layer we calculated the monthly mean values of zonal, $u_{0}$, and meridional, $v_{0}$, drift velocities, and the respective variances of short-period perturbations, $\bar{u}^{2}$ and $\bar{v}^{2}$. In addition, we calculated the mean height for each layer, which can differ from its nominal value, due to different real distributions of reflection heights during the experiment.

To study average seasonal variations of the mean drift velocity and its short-period variances, we averaged monthly mean values mentioned above for each respective month over the interval from 1983 to 1999 . The results for zonal, meridional and total standard deviations of short-period fluctuations of drift velocity are shown in Fig. 1. One can see that at lower altitudes near $85 \mathrm{~km}$ both zonal and meridional standard deviations have the main maximum in summer and a smaller maximum in winter. This is consistent with the character of seasonal variations of gravity wave activity in the mesosphere, which was observed with the Japanese MU radar and with MF radars (Tsuda et al., 1990; Gavrilov et al., 1995; Nakamura et al., 1996).

At larger altitudes in Fig. 1 one can see a shift in the summer maximum of the zonal standard deviation towards the spring months, and the formation of another maximum in autumn at altitudes near and above $100 \mathrm{~km}$. Seasonal variations of the meridional standard deviation in Fig. 1 have maxima in spring and summer, with the increase in the summer maximum at altitudes above $100 \mathrm{~km}$. Comparison of plots for zonal and meridional standard deviations in Fig. 1 reveal the lack of the autumn maximum of the meridional component, which is observed for the zonal one. The reasons for differences in the seasonal variations of the zonal and meridional components could be the differences in the seasonal variations of the mean zonal and meridional winds in the lower and middle atmosphere, as well as the differences in the wave generation at different altitudes. To study these effects we performed numerical modeling of seasonal variations of gravity wave intensity, which will be described in the following section.

\section{Numerical model}

\subsection{Model description}

The numerical model used in our study is described in detail by Gavrilov and Fukao (1999). The model calculates the vertical distributions of parameters of IGW harmonics assuming horizontal wave velocity variations in the form of

$u=V e^{i(\sigma t-k x)}$,

where $u$ is the wave perturbation velocity component along the axis $x$ directed along the horizontal wave vector; $V, \sigma$
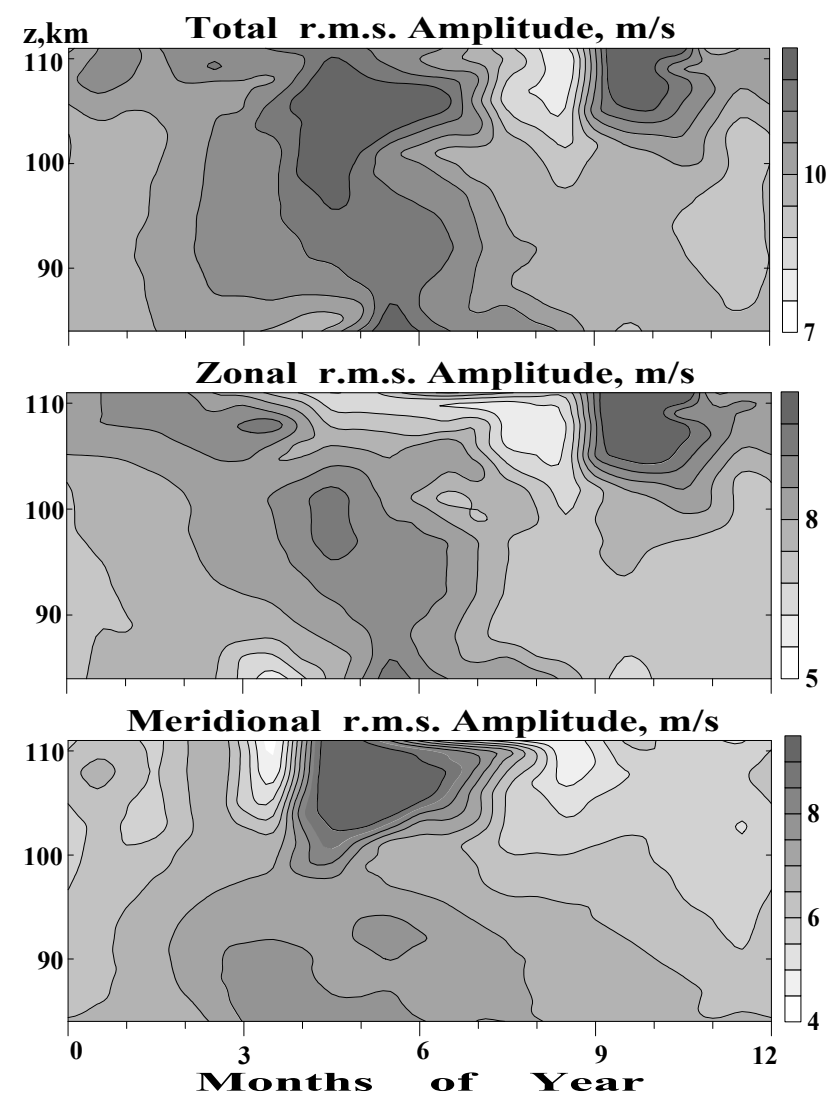

Fig. 1. Standard deviations of ionospheric drift velocity perturbations with periods $0.7-3 \mathrm{~h}$ averaged for each respective month over years 1983-1999.

and $k$ are the amplitude, observed frequency and horizontal wave number, respectively. In a stationary and horizontally homogeneous background atmosphere, the following equation describing the balance of the wave activity is valid for each wave harmonic (see Gavrilov and Fukao, 1999):

$\frac{\partial F_{a z}}{\partial z}=\frac{\rho_{0}}{\omega}\left(s V-\frac{N_{d}}{2} V^{2}\right), \quad F_{a z}=\frac{\rho_{0}}{m} \frac{V^{2}}{2}$,

where $F_{a z}$ is the vertical flux of the wave action; $\rho_{0}$ is the background atmospheric density; $\omega$ and $m$ are the intrinsic frequency and vertical wave number, respectively; $N_{d}$ is the rate of IGW dissipation due to turbulent and molecular viscosity and heat conduction, radiative heat exchange and ion drag.

The parameter $s$ in Eq. (2) describes the strength of nonlinear hydrodynamic sources in the atmosphere (see Gavrilov and Fukao, 1999). The main contribution to these sources gives Lighthill-type IGW generation by mesoscale meteorological motions (see Lighthill, 1952, 1978; Stein, 1967), which form mesoscale turbulence in the atmosphere with random distributions of hydrodynamic fields. Each random turbulent vortex is supposed to generate an IGW pulse with temporal and spatial scales comparable with the scales of the vortex. Therefore, at relatively long periods of time, these turbulent hydrodynamic IGW sources may be considered as 

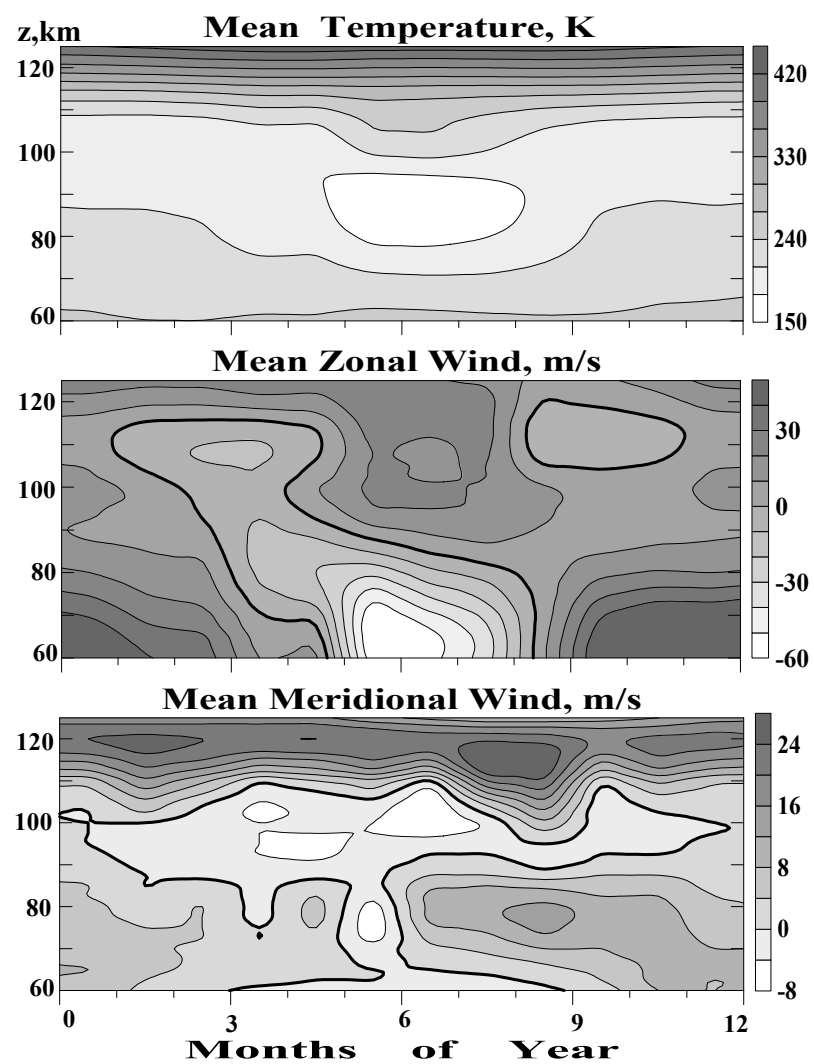

Fig. 2. The background temperature and wind components for the locations of the Collm Observatory.

randomly distributed inside the atmosphere. Gavrilov and Fukao (1999) supposed that each elementary wave source generates its own IGW with random frequency, $\sigma$, horizontal phase speed, $c=\sigma / k$, and the azimuth of propagation $\varphi$. The wave harmonics from different sources produce a statistical ensemble of IGWs. The average variance of horizontal velocity made by this ensemble may be calculated as

$U^{2}=\frac{1}{2} \sum_{i, j, k} V_{i j k}^{2} P\left(\sigma_{i}, c_{j}, \varphi_{k}\right)$,

where $P\left(\sigma_{i}, c_{j}, \varphi_{k}\right)$ is the probability that the IGW harmonics have $\sigma \in\left[\sigma_{i}, \sigma_{i+1}\right], c \in\left[c_{i}, c_{i+1}\right]$, and $\varphi \in\left[\varphi_{k}, \varphi_{k+1}\right]$. Assuming that the random wave sources produce IGWs with uniform distribution of $\sigma, c$ and $\varphi$ and that these quantities are statistically independent, Gavrilov and Fukao (1999) have obtained the expression

$P\left(\sigma_{i}, c_{j}, \varphi_{k}\right)=\frac{d \sigma_{i}}{\Delta \sigma} \frac{d c_{j}}{\Delta c} \frac{d \varphi_{k}}{\Delta \varphi}$,

where $d \sigma_{i}, d c_{j}, d \varphi_{k}$ are bins and $\Delta \sigma, \Delta c, \Delta \varphi$ are the total ranges of $\sigma, c$ and $\varphi$, respectively. This supposition of statistical independence of $\sigma$ and $c$ does not contradict the existence of the IGW dispersion relation. The latter connects $\sigma$, $c$ and the vertical wave number, $m$. Therefore, two of abovementioned IGW parameters ( $\sigma$ and $c$ in our model) may be considered as statistically independent. Using Eqs. (3) and
(4), one may solve Eq. (2) for a selection of IGW harmonics with an arbitrary set of $\sigma_{i}, c_{j}, \varphi_{k}$ and after that one may obtain the average variances produced by the ensemble of IGW harmonics generated by random sources. The strength of the wave sources in Eq. (2) may depend on $c, \sigma$ and $\varphi$. Assuming a separability of IGW spectra, Gavrilov and Fukao (1999) used the following formulae

$$
\begin{aligned}
s\left(\sigma, c, \varphi, v_{0}, N\right) & =S\left(V_{0}, N\right) F_{\sigma}(\sigma) F_{c}(c) \Phi(\varphi) ; \\
F_{\sigma}(\sigma) & =\frac{1}{1+\left(\sigma / \sigma_{0}\right)^{\alpha}}, \\
F_{c}(c) & =\frac{1}{1+\left(c / c_{1}\right)^{\beta}+\left(c_{2} / c\right)^{\gamma}},
\end{aligned}
$$

where $\alpha, \beta, \gamma$ and $\sigma_{0}, c_{1}, c_{2}$ are constants; $N$ is the BruntVäisälä frequency and $V_{0}$ is the mean wind speed. The functions $F_{\sigma}(\sigma)$ and $F_{c}(c)$ decrease at large $\sigma$, small and large $c$, as might be expected for turbulent flows (Monin and Yaglom, 1971). Lidar measurements (Gardner et al., 1995; Gardner, 1996) gave some evidences of non-separability of atmospheric perturbation spectra. But these measurements also showed the inadequacy of all existing non-separable theories (Gardner, 1996). Therefore, in the simple model presented here we use Eq. (5), where the azimuthal function $\Phi(\varphi)$ is related to the azimuth, $\varphi_{0}$, of the mean wind as follows:

$$
\begin{gathered}
\Phi(\varphi)=\left[\left(B_{1}+\cos \left(\varphi-\varphi_{0}\right)\right)^{1 / 2}+\left(B_{2} \sin \left(\varphi-\varphi_{0}\right)\right)^{2}\right]^{1 / 2} \\
/\left(1+B_{1}\right),
\end{gathered}
$$

where $B_{1}$ and $B_{2}$ are constants.

The main contribution to IGW nonlinear hydrodynamic sources is given by nonlinear advective accelerations involved in the hydrodynamic equation (see Drobyazko and Krasilnikov, 1985). Observations of the advective accelerations in the troposphere and stratosphere with the Japanese MU radar (see Gavrilov and Fukao, 2001) show their strong dependence on the mean wind velocity, $V_{0}$. We may also expect a dependence of $s$ on $N$, which may influence the intensity of turbulent and convective motions in the atmosphere. Gavrilov and Fukao (1999) supposed the following form for $S\left(V_{0}, N\right)$ in Eq. (5):

$S\left(V_{0}, N\right)=S_{0} V_{0}^{n} / N^{q}$,

where $S_{0}, n$ and $q$ are constants. They made numerical experiments with the model and found seasonal variations of IGW parameters at different altitudes in the middle atmosphere to be comparable with the MU radar measurements at $n \sim 1.5-2$. Although there is no reliable physical justifications for the choice of described randomly distributed gravity-wave sources, we have chosen to pursue this modeling technique, since it corresponds to general suggestions about the IGW spectrum in the atmosphere, and it is not computationally intensive and is simpler to interpret than more complex gravity wave models.

\subsection{Background atmosphere}

Equations (2)-(7) are solved here for a set of IGW harmonics representing a statistical ensemble of waves propagating 
from random IGW sources. The background temperature and wind components for altitudes $60-125 \mathrm{~km}$ are presented in Fig. 2. For altitudes between $30-85$ and $110-125 \mathrm{~km}$ they are taken from the MSISE-90 and HWM-93 models (Hedin, 1991; Hedin et al., 1996) for different months of the year for the location of the Collm Observatory. At altitudes between $0-30 \mathrm{~km}$ we used monthly mean temperatures and winds taken from the NCAR reanalysis database, averaged over the years 1980-1999. At altitudes between 85 and $110 \mathrm{~km}$ the mean winds were obtained from the Collm measurements simultaneously with the standard deviations of wind perturbations described in Sect. 2 above. Note that these mean drift velocities are not necessarily equal to the prevailing winds at Collm published previously (e.g. Jacobi et al., 1997b), because we did not make an extraction of tides here. But calculated in the manner used here, the mean velocities better reflect the true background conditions corresponding to the drift velocity measurements.

Equation (2) contains the rate of IGW dissipation, $N_{d}$, due to turbulent and molecular viscosity and heat conduction, ion drag, and radiative heat exchange (see Gavrilov, 1990). These characteristics are calculated here as described by Gavrilov and Fukao (1999). One of the main mechanisms of IGW dissipation in the atmosphere is small-scale turbulence due to wave breaking caused by dynamical and convective instability (Lindzen, 1981). In our model above the IGW breaking level of the coefficient of turbulent diffusion is calculated using the semi-empirical model by Gavrilov and Yudin (1992). To smooth the growth of turbulent viscosity from zero at low altitudes to the large values corresponding to IGW saturation above the wave breaking level, we use the formula for the effective coefficient of turbulence produced by the spectrum of irregular secondary harmonics given by Rozenfeld (1983), below the IGW breaking level. Other details of the calculation of turbulent and diffusion characteristics in our model are described by Gavrilov and Fukao (1999).

\section{Results of calculations}

The set of Eqs. (2)-(7) is solved for the background atmosphere representing different months of the year at the location of the Collm observatory (see Fig. 2). The numerical method used is described by Gavrilov (1990); the vertical step of integration is $250 \mathrm{~m}$. The equations are solved for a set of $50 \times 50 \times 12$ IGW harmonics, where multipliers denote the numbers of wave harmonics with different frequencies, horizontal phase speed and azimuths, respectively. Our model uses simplified dispersion and polarization relations suitable for low-frequency, short IGWs having $\sigma^{2} \gg N^{2}$ and $c^{2} \ll 4 H^{2} N^{2}$, where $H$ is atmospheric scale height. The assumption that the model profiles of background wind and temperature constant in time may be valid only for IGWs with periods much smaller than periods of diurnal and semidiurnal atmospheric tides. Therefore, IGW parameters in our calculations cover the ranges of fre-
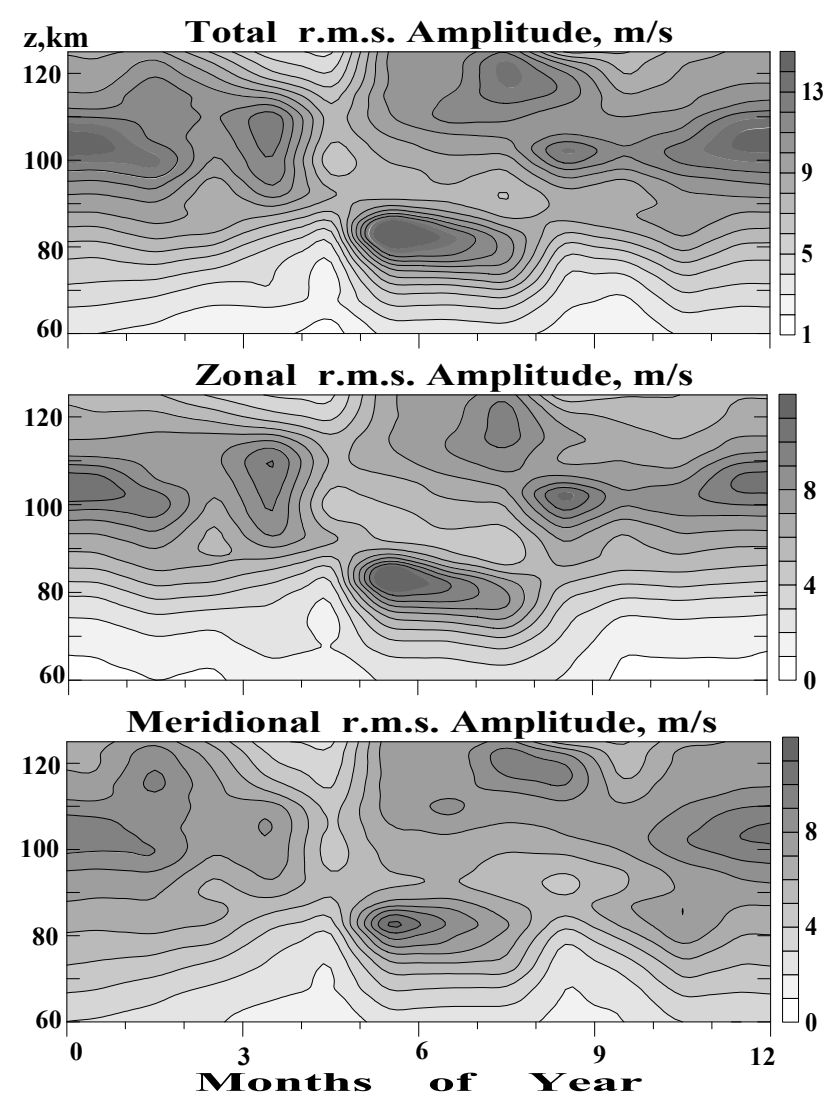

Fig. 3. Calculated seasonal-altitude distributions of standard deviations of total (upper), zonal (middle) and meridional (bottom) wind speed produced by the set of harmonics modeling IGW spectrum.

quencies $\sigma \sim(1.2-3) \times 10^{-3} \mathrm{rad} \mathrm{s}^{-1}$, horizontal phase speed $c \sim 3-100 \mathrm{~m} \mathrm{~s}^{-1}$, and azimuths $\varphi \sim 0-360^{\circ}$. We use uniformly spaced grids for $\ln \sigma, \ln c$, and $\varphi$ coordinates. The values of constants determining the spectral distributions of the wave sources in Eqs. (5)-(6) are basically the same as those used by Gavrilov and Fukao (1999), namely: $\sigma_{0}=1 \times 10^{-4} \mathrm{rad} \mathrm{s}^{-1}, \alpha=5 / 6, c_{1}=10 \mathrm{~m} \mathrm{~s}^{-1}$, $\beta=1, c_{2}=4 \mathrm{~m} \mathrm{~s}^{-1}, \gamma=1.5, B_{1}=0.5, B_{2}=0.1$. Parameters $\alpha$ and $\gamma$ are chosen to provide IGW power spectral slopes of $\sigma^{-5 / 3}$ and $m^{-3}$ at large $\sigma$ and $m$, corresponding to some observations and theoretical studies (Van Zandt, 1982), taking into account that the IGW power is proportional to $V^{2}$, or $s^{2}$ in our model. Other parameters are chosen to give the best fit of the calculated results to observations (see below).

Gavrilov and Fukao (1999) showed that the model may reproduce a realistic seasonal variation of the IGW intensity in the troposphere and mesosphere at $n=2$ in Eq. (7). Strong dependence of the intensity of wave sources on the mean wind in the atmosphere is confirmed by recent MU radar measurements of nonlinear advective accelerations (Gavrilov and Fukao, 2001). Therefore, in our calculations we use the values $n=2, S_{0}=3 \times 10^{-3} \mathrm{~m}^{-1} \mathrm{~s}^{-2}$ and $q=2$ in Eq. (7).

Figure 3 shows the calculated seasonal-altitude distributions of the standard deviations (called the mean wave 


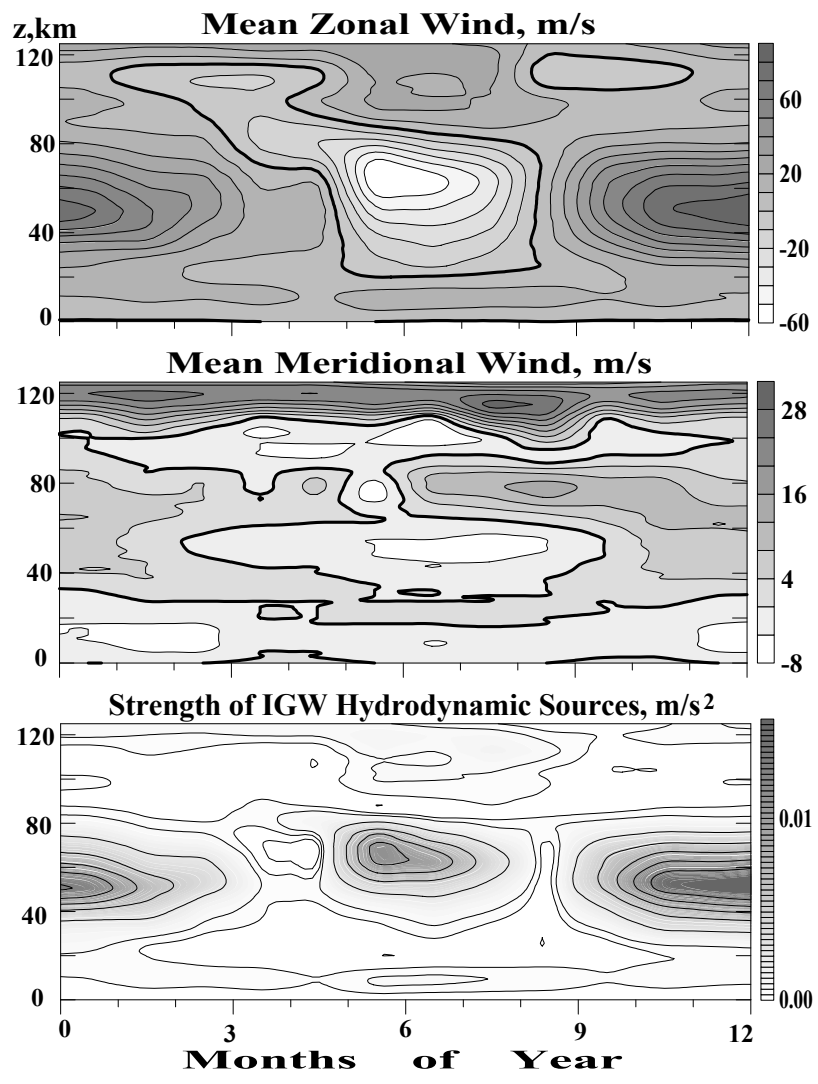

Fig. 4. Vertical-seasonal distributions of the mean zonal (top), meridional (middle) wind components and the strength of wave sources (bottom).

amplitudes below) produced by the set of harmonics for modeling the IGW spectrum described above. The zonal amplitude near altitude $80 \mathrm{~km}$ has the main maximum in summer and a smaller maximum in winter. At altitudes near and above $100 \mathrm{~km}$ one can see the maxima in winter, spring and autumn for the zonal amplitude in Fig. 3. The meridional amplitude has the main maximum in summer and a smaller maximum in winter near $80 \mathrm{~km}$ altitude in Fig. 3. Near $100 \mathrm{~km}$ we see the maxima of the meridional amplitude in winter, spring and summer, and almost no maximum in autumn. Such behavior broadly corresponds to the observed changes in seasonal variations of zonal and meridional standard deviations of drift velocities over Collm, which are shown in Fig. 1. The main differences are the larger winter values of IGW amplitudes calculated by the model near $100 \mathrm{~km}$ altitude compared to the observed ones (cf. Figs. 1 and 3).

In our model the seasonal variations of IGW amplitudes are caused by changes in the background atmospheric fields and in the strength of IGW hydrodynamic sources s, which, according to Eq. (7), depends on the mean wind. Height-time cross sections of the mean wind components and the strength of wave sources are shown in Fig. 4. One can see the maxima of IGW sources in the upper troposphere, stratosphere, mesosphere and lower thermosphere, which correspond to the main zonal jet streams existing at these regions of the

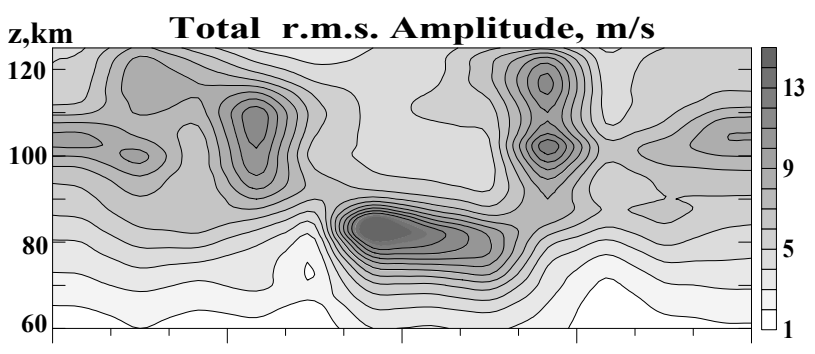

Zonal r.m.s. Amplitude, m/s

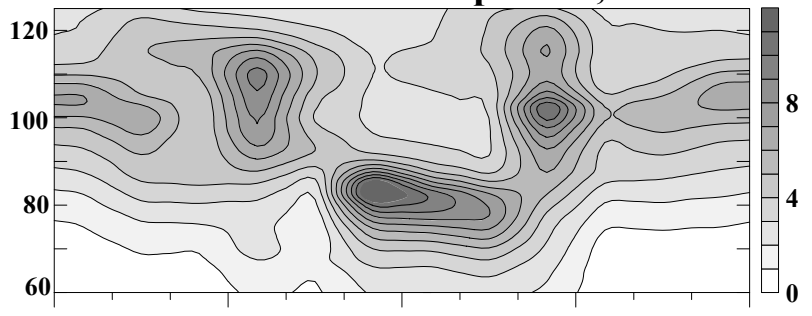

Meridional r.m.s. Amplitude, $\mathbf{m} / \mathbf{s}$

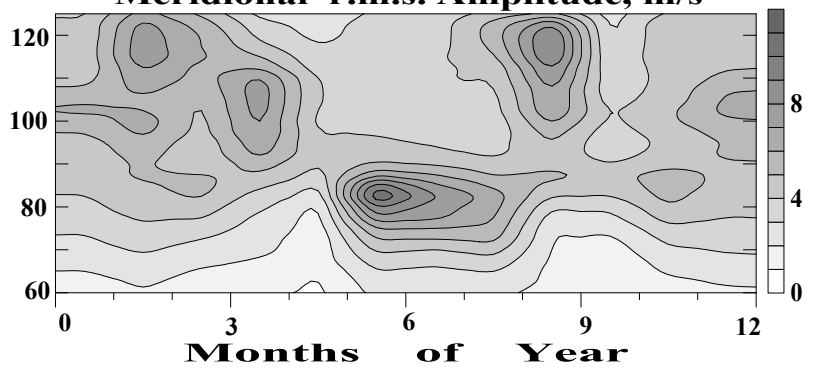

Fig. 5. Same as Fig. 3, but for IGW sources located below altitude $20 \mathrm{~km}$.

atmosphere. Figure 4 shows that the strength of the IGW sources in winter and summer is smaller in the troposphere over Collm than in the stratosphere and mesosphere. This is different from the approximate equality of tropospheric and stratospheric/mesospheric wave sources in winter presented by Gavrilov and Fukao (1999), due to a stronger tropospheric winter jet stream over Japan. Therefore, one may expect larger contribution of IGWs generated in the middle atmosphere at Collm.

To study the relative contributions of different hydrodynamic sources, we made calculated IGW amplitudes for model runs with non-zero wave sources specified below and above $20 \mathrm{~km}$ altitude separately. These results are shown in Figs. 5 and 6, respectively. One can see that the wave sources located at different altitudes tend to produce different types of IGW seasonal variations in the upper atmosphere.

Both zonal and meridional IGWs calculated for sources specified below $20 \mathrm{~km}$ have the maxima in spring and autumn above $90 \mathrm{~km}$ altitude in Fig. 5. At the same time, both IGW components in the run with sources located above $20 \mathrm{~km}$ altitude have the maxima in winter and summer and minima at equinoxes above $90 \mathrm{~km}$ altitude in Fig. 6. The total seasonal variations of IGW amplitudes for sources specified at all altitudes and shown in Fig. 3 are, therefore, essentially the result of adding the waves generated in the lower and middle atmosphere. From Fig. 5 one can see that the equinox minima of 

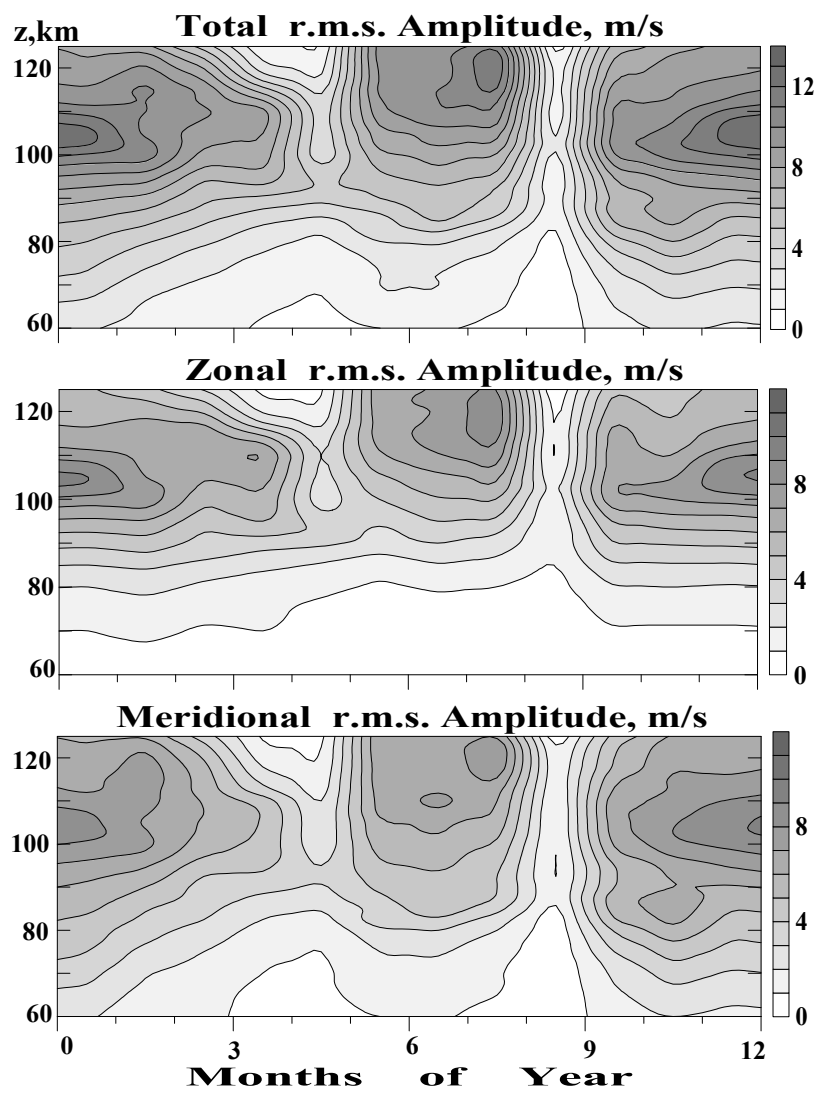

Fig. 6. Same as Fig. 3, but for IGW sources located above altitude $20 \mathrm{~km}$.

amplitudes of IGWs generated above $20 \mathrm{~km}$ tend to reduce the respective maxima made by tropospheric IGWs shown in Fig. 5.

Zonal IGW amplitudes in Fig. 5 have larger equinox maxima than those for the meridional component. Hence, the equinox maxima still exist in seasonal variations of the zonal IGW amplitude in Fig. 3, while the autumn maximum has completely disappeared for the meridional component. Therefore, different seasonal variations of zonal and meridional IGW amplitudes in Fig. 3 could be explained by a combined effect of IGWs generated at different levels in the atmosphere.

Important characteristics for the energetics and dynamics of the middle and upper atmosphere are the turbulent viscosity produced by breaking IGWs, heating rates due to wave dissipation and acceleration of the mean flow by dissipating waves. Our model provides the possibility to calculate these values, and their calculated seasonal variations are presented in Fig. 7. The main maxima of turbulent viscosity and IGW heating rates are located near altitude $80 \mathrm{~km}$ in summer and near and above $100 \mathrm{~km}$ in winter and summer in Fig. 7. IGW zonal accelerations are eastward near $80 \mathrm{~km}$ in summer and above $110 \mathrm{~km}$ at equinoxes, and are westward at other altitudes and seasons. The maximum eastward IGW accelerations are near altitude $80 \mathrm{~km}$ in summer and near and above
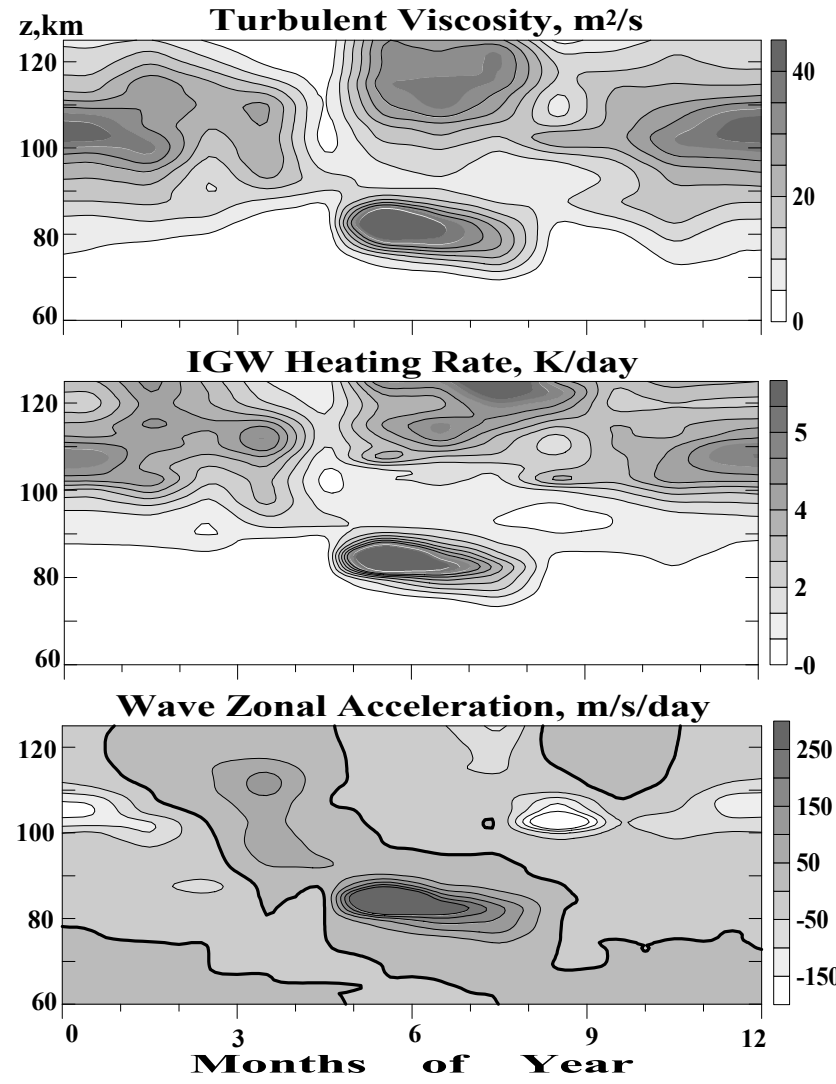

Fig. 7. Calculated seasonal-altitude variations of turbulent viscosity (top), heating rate (middle) and zonal wave acceleration of zonal flow (bottom) produced by the set of IGW harmonics.

$100 \mathrm{~km}$ in spring. The largest westward zonal accelerations are near and above $100 \mathrm{~km}$ in winter and autumn in Fig. 7.

In Figs. 8 and 9 the same parameters as in Fig. 7 are presented, but for IGW sources located at altitudes below and above $20 \mathrm{~km}$, respectively. From Fig. 8 one can see that the summer maximum of turbulent viscosity and IGW heating rates near altitude $80 \mathrm{~km}$ and equinox maxima near and above $100 \mathrm{~km}$ are produced by IGWs propagated from the lower atmosphere. Waves generated above $20 \mathrm{~km}$ produce winter and summer maxima of turbulent viscosity near and above altitude $100 \mathrm{~km}$ (see Fig. 9).

Zonal wind accelerations produced by lower sources (Fig. 8) are directed to the east in summer and to the west in winter above $80 \mathrm{~km}$ altitude, thus opposite to the directions of the main stratospheric/mesospheric jet. The directions of the accelerations produced by IGWs generated above $20 \mathrm{~km}$ in Fig. 9 have a more complicated structure. Total turbulent viscosities, IGW heating rates and wave accelerations presented in Fig. 7 are the superpositions of those characteristics produced by IGW sources located at all altitudes. 


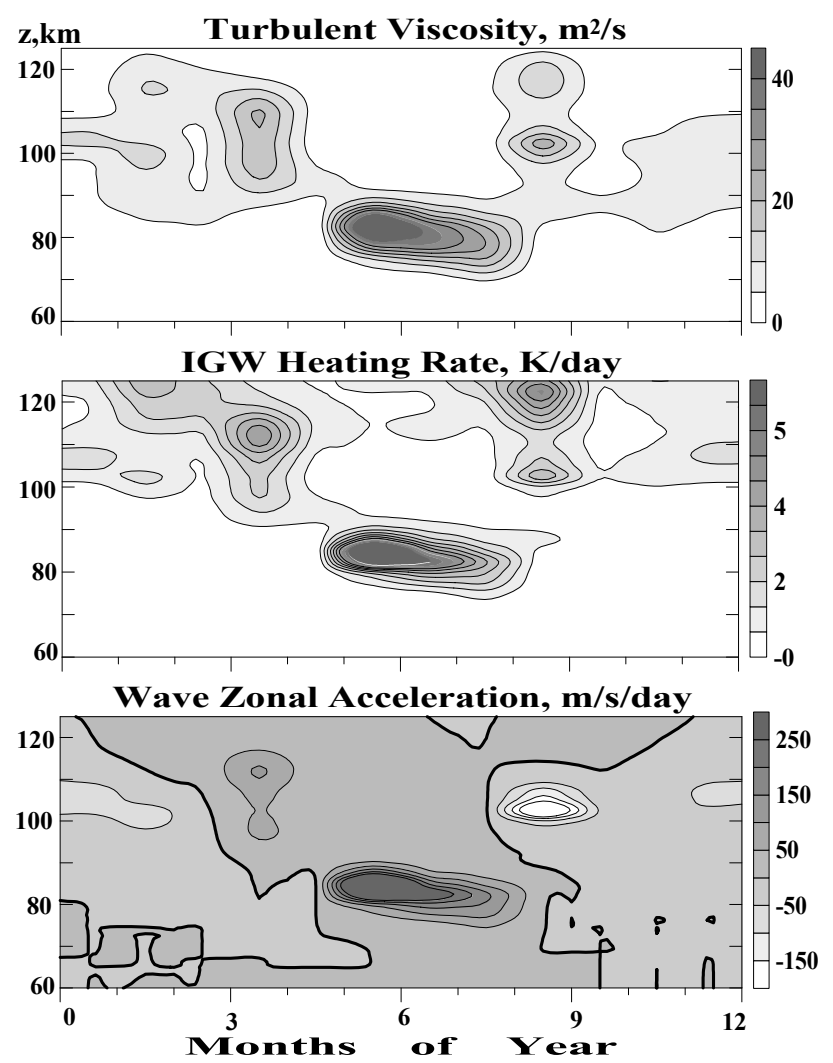

Fig. 8. Same as Fig. 7, but for IGW sources located below altitude $20 \mathrm{~km}$.

\section{Discussion}

Two questions may arise when considering the LF D1 measurements of the dynamics of the middle atmosphere. First, whether the measured ionospheric drifts reflect motions of the neutral atmosphere. Second, whether the similar-fade drift measurements used at Collm Observatory may show ionospheric motions that are not real, but rather motions of the reflection point due to the deformation of the mean electron density pattern.

The first question has been extensively discussed in the literature, and was proved both by theoretical consideration and by comparisons of the LF D1 drift velocities with winds obtained with other types of radars. Dieminger (1952), Jones (1958), Sprenger (1958), Schminder (1964) showed that the neutral forces in the lower E-region are the major contributions to the electron dynamics in the lower ionosphere due to the relatively high collision frequencies. As has been pointed out by Sprenger (1958), only some very large individual drift velocity values may have substantial contribution of electric forces. At Collm this is taken into account by rejecting individual drift velocities larger than $100 \mathrm{~m} / \mathrm{s}$. From the analysis of rocket data Larsen (2000) showed the frequent presence of very strong wind velocities at heights above $95 \mathrm{~km}$. Therefore, the estimations of drift velocity variances obtained from Collm data might be underestimated.

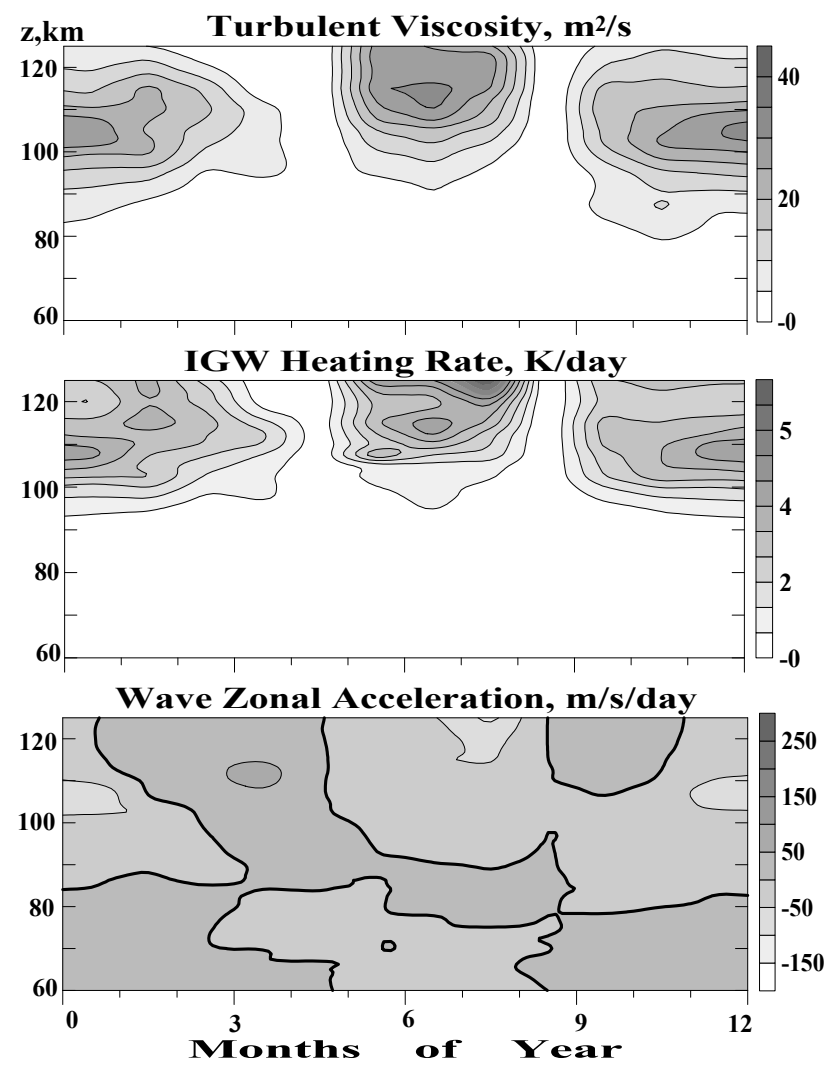

Fig. 9. Same as Fig. 7, but for IGW sources located above altitude $20 \mathrm{~km}$.

In the early stages of using LF drifts for wind measurements there has been a discussion as to whether the use of the similar-fade analysis procedure is suitable. Certainly, individual drift measurements from the similar-fade method are affected by the deformation and anisotropy of the electron density pattern, so that we use an averaging procedure (see Sprenger et al., 1974), assuming that there is no preferred deformation angle of the pattern. Therefore, the LF D1 method certainly cannot be used, for example, in the vicinity of the magnetic equator. For middle latitudes, however, it has been shown several times, both from theoretical estimations and from parallel calculations of winds using both similar fades and full correlation analysis (e.g. Sprenger et al., 1974), that the obtained wind parameters (half-hourly mean winds and chaotic velocity) are in good agreement. Moreover, comparisons of winds obtained with the Collm LF D1 measurements, medium frequency and meteor radars have been made several times (e.g. Hoffmann et al., 1990), showing good correlation of LF D1 half-hourly winds and those data derived from other systems.

In view of this discussion, an agreement between the calculated seasonal variations of IGW amplitudes and measured LF D1 drift velocity standard deviations may show that the general statistical behaviour of drift velocity perturbations might be explained in terms of neutral irregular winds produced by IGWs in the atmosphere up to altitudes of 
100-120 km. Previously, Gavrilov and Fukao (1999) showed a good agreement of seasonal variations of wave amplitudes calculated with the same numerical model of IGW spectrum, with seasonal variations of irregular wind intensity measured with the Japanese MU radar in the troposphere/stratosphere (altitudes 5-20 km) and mesosphere $(60-85 \mathrm{~km})$. Comparison of model results and LF D1 measurements at higher altitudes $85-110 \mathrm{~km}$ made in the present investigation now gives complimentary evidence about dramatic changes in seasonal variations of IGW amplitudes with height, which may be caused by seasonal variations of background wind and temperature patterns in the atmosphere and corresponding changes in the wave hydrodynamic sources.

In the previous section we showed that our model gives the possibility to calculate seasonal variations of such important characteristics as turbulent viscosity, heating rates and accelerations of the mean wind produced by breaking IGWs. It is interesting to compare our calculations of these characteristics with observations. Most recent estimates of seasonal variations of the turbulent viscosity and the turbulent energy dissipation rate (Lübken, 1997; Hall et al., 1998, 1999) are available for latitudes higher than the latitude of Collm Observatory used in our observations. Hall et al. (1999) showed good agreement of in situ rocket and radar measurements, giving a difference in seasonal variations of turbulent characteristics at different heights. Below $80-85 \mathrm{~km}$ the turbulent energy dissipation rates have mainly an annual cycle, with a maximum in winter and minimum in summer. Above altitudes $80-85 \mathrm{~km}$ relatively low turbulence levels in the equinoxes lead to a semiannual variation of turbulent characteristics.

Our calculations in Fig. 7 show the equinox minima of turbulent viscosity, but have a summer maximum above an altitude of $70 \mathrm{~km}$ that is lower than the observed one. The difference between the calculations and observations discussed above may be connected with a lower intensity of tropospheric and stratospheric/mesospheric jet streams and a stronger filtering effect of the summer background temperature field at stratospheric and mesospheric heights at high latitudes, which decreases the intensity of IGWs propagating from the lower atmosphere in summer. Estimates of turbulence intensity in the lower ionosphere at latitude of $39^{\circ}$ show the main maximum in summer. Measurements with the Japanese MU radar at $35^{\circ}$ latitude performed by Fukao et al. (1994) give the maximum of turbulent diffusivity near altitude $70-75 \mathrm{~km}$ in summer, which better corresponds to our calculations. Orders of magnitude of turbulent viscosity and the IGW heating rate in Fig. 7 correspond to the respective turbulent values $2-200 \mathrm{~m}^{2} / \mathrm{s}$ and $0.1-10 \mathrm{~K} /$ day observed by Hall et al. (1999) and Lübken (1997) at 60-100 km altitude, taking into account that the main portion of IGW energy dissipates through turbulence there.

The directions of wave zonal accelerations shown in Fig. 7 are mainly opposite to the directions of the mean zonal wind from Figs. 2 and 4. This confirms the suggestions about the IGW drag of the mean flow, which is important for the formation of the general circulation of the middle atmosphere
(Lindzen, 1981; Matsuno, 1982; Holton, 1983; Gavrilov, 1990; Fritts and Lu, 1993).

\section{Conclusion}

In this paper, the intensity of short-period perturbations of the horizontal drift velocity is estimated at the $85-110 \mathrm{~km}$ altitude from the data of the regular LF D1 E-region observations at Collm, Germany in 1983-1999. A simple halfhourly-difference numerical filter is used to extract perturbations with time scales of $0.7-3 \mathrm{~h}$.

The average monthly standard deviations of short-period perturbations of the zonal velocity near altitude $83 \mathrm{~km}$ have a main maximum in summer, a smaller maximum in winter, and minimum values at the equinoxes. At higher altitudes the summer maximum is shifted towards spring months, and a second maximum of perturbation amplitudes appears in autumn at altitudes near and above $100 \mathrm{~km}$. The seasonal changes in the standard deviations of meridional velocity show the maxima in spring and summer, and also some indications of an increase of the summer maximum at altitudes higher $100 \mathrm{~km}$.

Numerical modeling shows that the observed altitude changes in the seasonal variations of the drift velocity standard deviations may be explained by a superposition of IGWs generated at different levels in the troposphere and middle atmosphere. IGWs generated in the stratospheric and mesospheric jet stream may have substantial amplitudes at altitudes near and above $100 \mathrm{~km}$, where they may modify the seasonal variations, which are typical for IGWs propagating from the troposphere.

Acknowledgements. This study was partly supported by the International Association for the promotion of cooperation with scientists from the New Independent States (INTAS) under grant INTAS991-1186. The NCAR meteorological reanalysis data were kindly supplied by Dr. Chi-Fan-Chin. The authors thank Dr. D. Kürschner, Collm, for continuously measuring winds at Collm Observatory.

Topical Editor M. Lester thanks A. Ebel and another referee for their help in evaluating this paper.

\section{References}

Alexander, M. J.: A simulated spectrum of convectively generated gravity waves; Propagation from the tropopause to the mesosphere and effects on the middle atmosphere, J. Geophys. Res., 101, 1571-1588, 1996.

Chunchuzov, I. P.: On a possible generation mechanism for nonstationary mountain waves in the atmosphere, J. Atmos. Sci., 51, 2196-2206, 1994.

Dieminger, W.: Bewegungsvorgänge in der Ionosphäre. Ber. Dtsch. Wetterdienst 35, 224-227, 1952.

Drobyazko, I. N. and Krasilnikov, V. N.: Acoustic-gravity wave generation by atmospheric turbulence. Radiophysics, Izvestia of VUZ of USSR, 28, 1357-1365, 1985.

Fritts, D. C.: Shear excitation of atmospheric gravity waves, 2. Nonlinear radiation from a free shear layer, J. Atmos. Sci., 41, 524537, 1984. 
Fritts, D. C. and Lu, W.: Spectral estimates of gravity wave energy and momentum fluxes. Part 2: Parameterization of wave forcing and variability, J. Atmos. Sci., 50, 3695-3713, 1993.

Fritts, D. C. and Nastrom, G. D.: Sources of mesoscale variability of gravity waves, Part 2: Frontal, convective and jet stream excitation. J. Atmos. Sci., 49, 111-127, 1992.

Fukao, S., Yamanaka, M. D., Ao, N., Hocking, W. K., Sato, T., Yamamoto, M., Nakamura, T., Tsuda, T., and Kato, S.: Seasonal variability of vertical eddy diffusivity in the middle atmosphere, 1, Three-year observations by the middle and upper atmosphere radar. J. Geophys. Res., 99, 18 973-18 988, 1994.

Gardner, C. S., Tao, X., and Papen, G. C.: Simultaneous lidar observations of vertical wind, Temperature and density profiles in the upper mesosphere: Evidence for nonseparability of Atmospheric perturbation spectra, Geophys. Res. Lett., 22, 2877-2880, 1995.

Gardner, C. S.: Testing theories of atmospheric gravity wave saturation and dissipation, J. Atmos. Terr. Phys., 58, 1575-1589, 1996.

Gavrilov, N. M.: Parameterization of accelerations and heat flux divergences produced by internal gravity waves in the middle atmosphere, J. Atmos. Terr. Phys., 52, 707-713, 1990.

Gavrilov, N. M., Manson, A. H., and Meek, C. E.: Climatological monthly characteristics of middle atmosphere gravity waves (100 min - 10 hr) during 1979-1993 at Saskatoon, Ann. Geophysicae, 13, 285-295, 1995.

Gavrilov, N. M., Jacobi, Ch., and Kürschner, D.: Climatology of ionospheric perturbations at Collm, Germany, Adv. Space Res., 27, 1779-1784, 2001.

Gavrilov, N. M. and Fukao, S.: A comparison of seasonal variations of gravity wave intensity observed with the middle and upper atmosphere radar with a theoretical model, J. Atmos. Sci., 56, 3485-3494, 1999.

Gavrilov, N. M. and Yudin, V. A.: Model for coefficients of turbulence and effective Prandtl number produced by breaking gravity waves in the upper atmosphere, J. Geophys. Res., 97, 76197624, 1992.

Gavrilov, N. M. and Fukao, S.: Hydrodynamic tropospheric wave sources and their role in gravity wave climatology of the upper atmosphere from the MU radar observations, J. Atmos. SolarTerr. Phys., 63, 931-943, 2001.

Hall, C. M., Manson, A. H., and Meek, C. E.: Seasonal variation of the turbopause: One year of turbulence investigation at $69^{\circ} \mathrm{N}$ by the joint University of Tromso/ University of Saskatchewan MF radar, J. Geophys. Res., 103, 28 769-28 773, 1998.

Hall, C. M., Hoppe, U. P., Blix, T. A., Thrane, E. V., Manson, A. H., and Meek, C. E.: Seasonal variation of turbulent energy dissipation rates in the polar mesosphere: a comparison of methods, Earth Planets Space, 51, 515-524, 1999.

Hamilton, K.: A study of the occurrence of dynamically unstable conditions in the middle atmosphere, Canad. J. Phys., 62, 963967, 1984.

Hedin, A. E.: Neutral atmosphere empirical model from the surface to lower exosphere MSISE-90, Extension of the MSIS thermosphere model into the middle and lower atmosphere, J. Geophys. Res., 96, 1159-1172, 1991.

Hedin, A. E., Fleming, E. L., Manson, A. H., Schmindlin, F. J., Avery, S. K., Clark, R. R., Franke, S. J., Fraser, G. J., Tsuda, T., Vial, F., and Vincent, R. A.: Empirical model for the upper, middle and lower atmosphere, J. Atmos. Terr. Phys., 58, 14211447, 1996.

Hoffmann, P., Singer, W., Keuer, D., Schminder, R., and Kürschner, D.: Partial reflection drift measurements in the lower ionosphere over Juliusruh during winter and spring 1989 and comparison with other wind observations, Z. Meteorol, 40, 405-412, 1990.

Holton, J. R.: The influence of gravity wave breaking on the general circultaion of the middle atmosphere, J. Atmos. Sci., 40, 24972507, 1983.

Jacobi, Ch., Schminder, R., Kürschner, D., Bremer, J., Greisiger, K. M., Hoffmann, P., and Singer, W.: Long-term trends in the mesopause wind field obtained from LF D1 wind measurements at Collm, Germany, Adv. Space Res., 20, 2085-2088, 1997a.

Jacobi, Ch., Schminder, R., and Kürschner, D.: Measurements of mesopause region winds over Central Europe from 1983 through 1995 at Collm Germany, Beitr. Phys. Atmos., 70(3), 189-200, 1997b.

Jones, I. L.: The height variations of drift in the E-region, J. Atmos. Terr. Phys. 12, 68-76, 1958.

Kürschner, D., Schminder, R., Singer, W., and Bremer, J.: Ein neues Verfahren zur Realisierung absoluter Reflexionshöhenmessungen an Raumwellen amplitudenmodulierter Rundfunksender bei Schrägeinfall im Langwellenbereich als Hilfsmittel zur Ableitung von Windprofilen in der oberen Mesopausenregion, Z. Meteorol., 37, 322-332, 1987.

Kürschner, D.: Konzeption und Realisierung eines vollautomatischen Registriersystems zur Durchführung von nach der D1-Methode angelegten Routinebeobachtungen ionosphärischer Driftparameter am Observatorium Collm, Z. Meteorol., 25, 218221, 1975.

Larsen, M. F.: Coqui 2: Mesospheric and lower thermospheric wind observations over Puerto Rico, Geophys. Res. Lett., 27, 445-448, 2000.

Lighthill, M. J.: On sound generated aerodynamically, 1. General theory, Proc. Roy. Soc. London, A211, 564-587, 1952.

Lighthill, M. J.: Waves in fluids, Cambridge Univ. Press, Cambridge, London, New York, Melbourne, Sydney, 1978.

Lindzen, R. S.: Turbulence and stress owing to gravity wave and tidal breakdown, J. Geophys. Res., 86, 9707-9714, 1981.

Lindzen, R. S.: Gravity waves in the mesosphere, Dynam. Middle Atmos., Dordrecht press, Tokyo, 3-18, 1984.

Lübken, F. J.: Seasonal variation of turbulent energy dissipation rates at high latitudes as determined by in situ measurements of neutral density fluctuations, J. Geophys. Res., 102, $13441-$ 13456, 1997.

Manzini, E. and Hamilton, K.: Middle atmospheric traveling waves forced by latent and convective heating, J. Atmos. Sci., 50, 21802200, 1993.

Matsuno, T.: A quasi-one-dimensional model of the middle atmosphere circulation interacting with internal gravity waves, J. Met. Soc. Japan, 60, 215-226, 1982.

McLandress, C. and McFarlane, N. A.: Interactions between orographic gravity wave drag and forced stationary planetary waves in the winter northern hemisphere middle atmosphere, J. Atmos. Sci., 50, 1966-1990, 1993.

Monin, A. S. and Yaglom, A. M.: Statistical Fluid Mechanics, 1, MIT Press, Cambridge, MA, 1971.

Nakamura, T., Tsuda, T., Fukao, S., Manson, A. H., Meek, C. E., Vincent, R. A., and Reid, I. M.: Mesospheric gravity waves at Saskatoon $\left(52^{\circ} \mathrm{N}\right)$, Kyoto $\left(35^{\circ} \mathrm{N}\right)$, and Adelaide $\left(35^{\circ} \mathrm{S}\right)$, J. Geophys. Res., 101, 7005-7012, 1996.

Nastrom, G. D. and Fritts, D. C.: Sources of mesoscale variability of gravity waves, Part 1: Topographic excitation. J. Atmos. Sci., 49, 101-110, 1992.

Pfister L., Scott, S., Loewenstein, M., Bowen, S., and Legg, M.: Mesoscale disturbances in the tropical stratosphere excited by 
convection, Observations and effects on the stratospheric momentum budget, J. Atmos. Sci., 50, 1058-1075, 1993.

Rozenfeld, S. H.: On the damping of internal gravity waves in the atmosphere due to generation of secondary harmonics, Atmosph. Oceanic Phys., Izvestia of USSR Acad. Sci., 19, 1011-1019, 1983.

Schminder, R.: Ionosphärische Driftmessungen im E-Schichtniveau am Geophysikalischen Observatorium Collm - ein Beitrag zur Zirkulation der Hochatmosphäre Veröffentlichungen des Geophysikalischen Instituts der Karl-Marx-Universität Leipzig, Ser. 2, 18(2), 79-275, 1964.

Schminder, R. and Kürschner, D.: Permanent monitoring of the upper mesosphere and lower thermosphere wind fields (prevailing and semidiurnal tidal components) obtained from LF D1 measurements in 1991 at the Collm Geophysical Observatory, J. Atmos. Terr. Phys., 56, 1263-1269, 1994.

Singer, W.: Bestimmung von Elektronenkonzentrationsprofilen der Mesosphäre und unteren Thermosphare aus Grundlage von Funkwellenausbreitungsdaten, Doctorate Thesis, Berlin, 130 pp., 1975.

Smith, S. A., Fritts, D. C., and Van Zandt, T. E.: Evidence of a saturation spectrum of atmospheric gravity waves, J. Atmos. Sci., 44, 1404-1410, 1987.
Sprenger, K.: Ionosphärendriftmessungen im Langwellenbereich als Beitrag zum Problem der allgemeinen Zirkulation der Hochatmosphäre, Z. Meteorologie, 12, 211-218, 1958.

Sprenger, K. and Schminder, R.: On some relationships between correlation analysis and similar-fade analysis results of drift measurements in the lower ionosphere, J. Atmos. Terr. Phys, 31, 1085-1098, 1969.

Sprenger, K., Schminder, R., Greisiger, K. M., Kürschner, D., and Schäning, B.: Die Windsysteme in der oberen Mesopausenregion mittlerer Breiten nach Ionosphärendriftmessungen im Langwellenbereich. Heinrich-Hertz-Institut, AdW, Berlin, HHI Report 2, 323 pp., 1974.

Stein, R. S.: Generation of acoustic and gravity waves by turbulence in an isothermal stratified atmosphere, Solar Phys., 2, 285-432, 1967.

Townsend, A. A.: Excitation of internal waves by a turbulent boundary layer, J. Fluid Mech., 22, 241-252, 1965.

Tsuda, T., Murayama, Y., Yamamoto, M., Kato, S., and Fukao, S.: Seasonal variations of momentum flux in the mesosphere observed with the MV radar, Geophys. Res. Lett., 17, 725-728, 1990.

Van Zandt, T. E.: A universal spectrum of buoyancy waves in the atmosphere, Geophys. Res. Lett., 9, 575-578, 1982. 